\title{
Gestational diabetes: know your risk by simple and single step criteria (DIPSI)
}

\author{
Gita Guin, Ruchita Dadhich*
}

Department of Obstetrics and Gynecology, N.S.C.B. Medical College Jabalpur, Madhya Pradesh, India

Received: 10 September 2017

Accepted: 05 October 2017

\section{*Correspondence:}

Dr. Ruchita Dadhich,

E-mail: drruchita.dadhich@gmail.com

Copyright: (C) the author(s), publisher and licensee Medip Academy. This is an open-access article distributed under the terms of the Creative Commons Attribution Non-Commercial License, which permits unrestricted non-commercial use, distribution, and reproduction in any medium, provided the original work is properly cited.

\begin{abstract}
Background: Gestational diabetes mellitus (GDM) has associations beyond the index pregnancy, identifying two generations at risk of future diabetes. Thus, detection of gestational diabetes mellitus becomes an important public health issue. This study aimed to estimate the prevalence of gestational diabetes mellitus by using simple and single step DIPSI criteria (Diabetes in pregnancy study group India) and risk factors associated with GDM.

Methods: This cross-sectional study was carried out in 800 antenatal patients attending the antenatal clinic. These patients have given $82.5 \mathrm{gm}$ mono-hydrous (75 gm anhydrous) oral glucose irrespective of the meals and their plasma glucose was estimated at $2 \mathrm{hr}$. Patients with plasma glucose value $\geq 140 \mathrm{mg} / \mathrm{dl}$ were diagnosed as GDM.

Results: The present study estimated that the prevalence of GDM was $14.75 \%$ at their 1st visit. We found a positive association of GDM by age, BMI, hypertension and family history of diabetes. Older women had 4.5 times greater risk of GDM than younger women, obese women had 52 times higher risk of GDM than underweight women and hypertensive pregnant women had 4 times greater risk of GDM.

Conclusions: It was realized that the test (DIPSI) could be easily performed in high volume hospitals comfortably and the patient were at ease as they were not fasting. Simple, cost effective tests, if made universal and available in developing country like ours will surely aid health care providers to screen, diagnose GDM and offer preventive and treatment measures at the earliest.
\end{abstract}

Keywords: Diabetes in pregnancy study group India criteria, Gestational diabetes mellitus

\section{INTRODUCTION}

Gestational diabetes mellitus (GDM) is characterized by carbohydrate intolerance of varying severity with onset or first recognition during pregnancy. ${ }^{1}$ GDM has associations beyond the index pregnancy, identifying two generations at risk of future diabetes. ${ }^{2}$ GDM is associated with increased pregnancy morbidity and increases the risk of subsequent type 2 diabetes in the mother. GDM also predisposes the offspring to an increased risk of developing glucose intolerance in the future. Thus, GDM women are an ideal group for the primary prevention of future diabetes. Early detection and management of women with GDM becomes necessary for better maternal and fetal outcome. The modified WHO test as proposed by Diabetes in Pregnancy Study Group India (DIPSI), does not require fasting, whereas WHO protocol mandates fasting state. Furthermore, DIPSI test is a single-step procedure which serves both as screening and diagnostic tool. It is the simplest test, feasible and has a high sensitivity to diagnose GDM, almost as high as the IADPSG (International Association of The Diabetes and Pregnancy Study Groups) testing. ${ }^{3}$

In 2015, IDF (International Diabetes Federation) estimated that one in seven births is affected by 
gestational diabetes and in South East Asia, one quarter of all births are affected by high blood glucose in pregnancy. ${ }^{4}$ It is estimated by IDF (International Diabetes Federation) that 20.9 million or $16.2 \%$ of live births to women in 2015 had some form of hyperglycemia in pregnancy. An estimated $85.1 \%$ of those subjects were due to gestational diabetes, $7.4 \%$ due to other types of diabetes first detected in pregnancy and $7.5 \%$ due to diabetes detected prior to pregnancy. The South-East Asia Region has the highest prevalence at $24.2 \%$ compared to $10.5 \%$ in the Africa Region. ${ }^{5}$ Majority $(87.6 \%)$ of subjects of hyperglycemia in pregnancy were in low and middle-income countries where access to maternal care is often limited.

GDM was detected in $17.8 \%$ women in urban, $13.8 \%$ in semi urban and $9.9 \%$ in rural areas. ${ }^{6}$ It varies with geographic location and has been reported to range from $3.8 \%$ in Kashmir, to $6.2 \%$ in Mysore, $9.5 \%$ in Western India and $17.9 \%$ in Tamil Nadu. ${ }^{7-10}$ In recent studies prevalence rates as high as 35\% from Punjab and $41 \%$ from Lucknow have been found. ${ }^{11,12}$ It is estimated that about 4 million women are affected by GDM in India, at any given time point. ${ }^{13}$ The prevalence of GDM shows increasing trends it was $2 \%$ in 1982 which increased to $7.62 \%$ in 1991 and doubled to $16.55 \%$ in $2002 .{ }^{14-16}$

The increased prevalence is because of urbanization, obesity, and physical inactivity. While all these factors contribute to the epidemic of diabetes, intrauterine exposures are emerging as potential risk factors. ${ }^{17}$ The "fetal origin of adult disease" hypothesis recommends that gestational programming may influence adult health and disease. ${ }^{17}$ In Gestational programming stimuli or stresses occurring at critical or sensitive periods of fetal development, permanently change structure, physiology, and metabolism, which predisposes individuals to disease in adult life. ${ }^{18}$ Hyperglycemia in pregnancy predisposes the offspring to an increased risk of developing glucose intolerance in the future. Therefore, preventive measures against type 2 diabetes should start during the intrauterine period. In this respect, detection of gestational diabetes mellitus (GDM) becomes an important public health issue. The etiopathogenesis of glucose intolerance that develops in women with GDM could be the result of their inability to increase insulin secretion enough to overcome insulin resistance that occurs even in non-diabetic pregnancy. The present concept is that chronic $\beta$ cell dysfunction, rather than development of relative insulin deficiency leads to development of GDM. ${ }^{19}$

As India is now rated as diabetes capital of the world, there is immense need for a sensitive, cost effective and feasible test to diagnose GDM so that preventive and therapeutic measures can be adopted to prevent adverse maternal and fetal outcome and lay down health care strategies for women in future. Universal screening for gestational diabetes mellitus (GDM) should be recommended as Indian women have 11 fold increased risk of developing GDM compared to Caucasians. ${ }^{21}$
This study aimed to estimate the prevalence of Gestational diabetes mellitus and to find out risk factors of Gestational diabetes mellitus in antenatal patients attending antenatal clinic at their first visit by using simple and single step criteria (DIPSI).

\section{METHODS}

The present cross-sectional study was conducted at the antenatal clinic in the Department of Obstetrics and Gynaecology during the period, 1st March 2015 to 31st August 2016. A total 800 antenatal subjects were counselled and screened by using DIPSI criteria ( $2 \mathrm{hr} 75$ gm post plasma glucose $\geq 140 \mathrm{mg} / \mathrm{dl}$, irrespective of the last meal timing) and prevalence of Gestational diabetes was estimated. The inclusion criteria included antenatal subjects attended their $1^{\text {st }}$ antenatal visit at the antenatal clinic in the Department of Obstetrics and Gynecology, while all patients with known diabetes and unwillingness for test were excluded.

The adequate required sample size was estimated using following formula

$$
\mathrm{N}=\mathrm{z}^{2} \mathrm{pq} / \mathrm{d}^{2}
$$

Where $-\mathrm{n}=$ sample size, $\mathrm{z}=1.96$ (considering 0.05 alpha, $95 \%$ confidence limits and $80 \%$ beta), $p=$ assumed probability of occurrence or concordance of results, $q=1$ $-\mathrm{p}, \mathrm{d}=$ marginal error (precession)

To calculate the adequate required sample size, we have taken assumptions that $15 \%$ probability with $2.5 \%$ absolute precision (12.5 - 17.5) would be targeted. This accumulates 783.7 by using above given formula. Therefore, minimum 800 subjects were adequate number for the study.

The study was initiated with the approval of the Institutional Ethics Committee. Informed consent was taken during initial assessment from all the patients. A detailed clinical assessment of patient was performed in the antenatal clinic and recorded in a standard proforma including general information on demographic characteristics, socio-economic status, education level, obstetric history, family history of diabetes, height, and pre-pregnancy weight and BMI. General physical examination and obstetric examination was done. Routine investigations were done. According to DIPSI (Diabetes in pregnancy study group of India) criteria $75 \mathrm{gm}$ anhydrous glucose or $82.5 \mathrm{gm}$ mono-hydrous glucose can be used. We used $82.5 \mathrm{gm}$ mono-hydrous glucose. $82.5 \mathrm{gm}$ glucose was given after dissolving in $200 \mathrm{~mL}$ water irrespective of the last meal timings. The intake of the solution should be completed within five minutes. In case vomiting occurred within 30 minutes of oral glucose intake, the test was repeated next day. But if it occurred after 30 minutes, the test continued. Venous blood was drawn after $2 \mathrm{hrs}$. The plasma glucose level was estimated by the glucose oxidase peroxidase (GOD-POD) 
method. Women with $2-\mathrm{hr}$ PG $\geq 140 \mathrm{mg} / \mathrm{dl}$ (DIPSI criteria) were diagnosed as GDM and rest were classified as normal glucose tolerant (NGT). Women diagnosed as GDM were managed extensively.

\section{Statistical analysis}

Data was entered in MS Office excel. The prevalence of GDM was estimated. All the quantitative variables were grouped accordingly. Chi-square test and ODDS ratio was calculated for each qualitative variable. Data analysis was done using STATA 12.1. P value less than 0.05 was considered as statistically significant.

\section{RESULTS}

A total 800 subjects screened by single and simple step DIPSI (Diabetes in pregnancy study group India) criteria, of which $118(14.75 \%)$ were diagnosed as GDM at their $1^{\text {st }}$ visit.

Table 1: Background characteristic of study subjects.

\begin{tabular}{|c|c|c|c|c|}
\hline Variables & & N/D (\%) & OR $(95 \% \mathrm{CI})$ & P Value \\
\hline \multirow{2}{*}{ Locality } & Rural & $55 / 471(11.67 \%)$ & 1 & \\
\hline & Urban & $63 / 329(19.14 \%)$ & $1.79(1.21-2.66)$ & 0.003 \\
\hline \multirow{4}{*}{ Occupation } & Housewife & $40 / 275(14.5 \%)$ & 1 & \\
\hline & Laborer & $56 / 360(15.6 \%)$ & $1.08(0.70-1.68)$ & 0.72 \\
\hline & Business & $16 / 120(13.3 \%)$ & $0.90(0.48-1.69)$ & 0.75 \\
\hline & Salaried Job & $6 / 45(13.3 \%)$ & $0.90(0.36-2.28)$ & 0.83 \\
\hline \multirow{5}{*}{ Educational status } & Illiterate & $19 / 170(11.2 \%)$ & 1 & \\
\hline & Primary & $30 / 265(11.3 \%)$ & $1.01(0.55-187)$ & 0.96 \\
\hline & Middle & $26 / 163(16 \%)$ & $1.51(0.79-2.85)$ & 0.20 \\
\hline & Higher Secondary & $36 / 142(25.4 \%)$ & $2.70(1.45-5.02)$ & 0.001 \\
\hline & College & $7 / 60(11.7 \%)$ & $1.05(1.42-2.64)$ & 0.92 \\
\hline \multirow{3}{*}{ Socio economic status } & Lower & $73 / 495(14.7 \%)$ & 1 & \\
\hline & Middle & $44 / 296(14.9 \%)$ & $1.01(0.67-1.51)$ & 0.96 \\
\hline & Higher & $1 / 9(11.1 \%)$ & $0.72(0.09-5.88)$ & 0.76 \\
\hline
\end{tabular}

*N = GCT Positive, $* \mathrm{D}=$ Total Subject

Table 2: Univariate logistic regression analysis for potential risk factors of gestational diabetes.

\begin{tabular}{|c|c|c|c|c|}
\hline \multicolumn{2}{|l|}{ Risk Factors } & N/D (\%) & OR $(95 \% \mathrm{CI})$ & P Value \\
\hline \multirow{3}{*}{$\begin{array}{l}\text { Age } \\
\text { (year) }\end{array}$} & $<20$ & $10 / 102(9.8 \%)$ & 1 & \\
\hline & $21-30$ & $84 / 625(13.4 \%)$ & $1.43(0.71-2.86)$ & 0.31 \\
\hline & $>30$ & $24 / 73(32.9 \%)$ & $4.51(1.92-10.58)$ & 0.0001 \\
\hline \multirow{4}{*}{ BMI } & $<18.5$ Underweight & $2 / 80(2.5 \%)$ & 1 & \\
\hline & 18.5-24.99 Normal weight & $63 / 518(12.16 \%)$ & $5.40(1.28-22.73)$ & 0.0098 \\
\hline & 25-29.99 Over weight & $33 / 167(19.76 \%)$ & $5.60(2.15-42.96)$ & 0.0003 \\
\hline & $>30$ Obese & $20 / 35(57.14)$ & $52.0(6.82-396.32)$ & $<0.0001$ \\
\hline \multirow{2}{*}{ Hypertension } & No & $83 / 700(11.86 \%)$ & 1 & \\
\hline & Yes & $35 / 100(35 \%)$ & $4.00(2.47-6.48)$ & $<0.0001$ \\
\hline \multirow{2}{*}{$\begin{array}{l}\text { Hypertension in } \\
\text { previous pregnancy }\end{array}$} & No & $107 / 770(13.9 \%)$ & 1 & \\
\hline & Yes & $11 / 30(36.7 \%)$ & $3.59(1.65-7.80)$ & 0.0006 \\
\hline \multirow{2}{*}{$\begin{array}{l}\text { H/o Diabetes in First } \\
\text { degree relative }\end{array}$} & No & $91 / 722(12.6 \%)$ & 1 & \\
\hline & Yes & $27 / 78(34.6 \%)$ & $3.67(2.17-6.21)$ & $<0.0001$ \\
\hline \multirow{2}{*}{$\begin{array}{l}\text { H/o Diabetes in Second } \\
\text { degree relative }\end{array}$} & No & $98 / 749(13.1 \%)$ & 1 & \\
\hline & Yes & $20 / 51(39.2 \%)$ & $4.29(2.33-7.90)$ & $<0.0001$ \\
\hline
\end{tabular}

Demographically (Table 1) most of the subjects i.e. 471 (58.87\%) belong to rural locality but urban pregnant women had 1.7 times higher risk of GDM [OR 1.79 (95\%CI 1.21-2.66)] which was statistically significant $(\mathrm{p}=0.003)$. Prevalence of GDM found more in labourer and middle socioeconomic class, whether it is because of study population bias is uncertain. This may be because of Malnutrition-related diabetes mellitus (MRDM). ${ }^{20}$ Present study observed that $16.1 \%$ GDM subjects were illiterate and $30.5 \%$ GDM subjects were educated up to 
higher secondary, this difference was statistically significant. Maximum prevalence found in Higher Secondary class, 36 out of 142 were diagnosed as GDM which was significant statistically $(\mathrm{P}=0.001)$.

In the present study, it was found that older age, BMI $>30$ $\mathrm{kg} / \mathrm{m}^{2}$, hypertension, history of hypertension in previous pregnancy and family history of diabetes mellitus was significantly associated with GDM. Table 2 shows that most of the study subjects 625 (78.12\%) belong to 21-30 year age group although Women with $>30$ years old were 4.5 times greater chances of GDM [OR 4.51(95\% CI $1.92-10.58)$ ] than younger $(\leq 20$ years old) which is significant statistically $(\mathrm{p}<0.0001)$. Analysis of GDM prevalence according to BMI revealed that obese pregnant women (BMI> 30) were more likely to GCT positive than underweight pregnant women $(\mathrm{BMI}<18.5)$. Obese pregnant women (BMI> 30) had 52 times more chances of GDM [OR 52(95\%CI 6.82-396.32)] which was significant statistically $(\mathrm{p}<0.0001)$. Further, overweight pregnant women (BMI 25-29.99) were found to have 5.6 times higher chances of GDM [OR $5.60(95 \%$ CI 2.15-42.96)] which was significant statistically $(\mathrm{p}<0.0003)$. We found significant correlation between GDM and Hypertension that Hypertensive pregnant women had 4 times greater risk of GDM [OR 4 (95\%CI (2.47-6.48)] and Pregnant women with history of hypertension in previous pregnancy had 3.59 times greater risk of GDM even at their $1^{\text {st }}$ visit [OR 3.59 (95\%CI 1.65-7.80)] which was also significant statistically $(\mathrm{p}<0.0006)$. As the diabetes runs in family and we also analyzed that Pregnant women with history of diabetes in first degree relatives had 3.6 times greater risk of GDM [OR 3.67 (95\%CI 2.17-6.21)] and Pregnant women with history of diabetes in second degree relatives had 4.2 times greater risk of GDM even at their 1st antenatal visit [OR 4.29 (95\%CI 2.33-7.90)] which was significant statistically $(\mathrm{p}<0.0001)$.

\section{DISCUSSION}

A study conducted by Seshiah V et al at Government Maternity Hospital Chennai, they found 18.9\% GDM prevalence when taking both FPG $\geq 126 \mathrm{mg} / \mathrm{dl}$ and/or $2 \mathrm{hr}$ PPG $\geq 140 \mathrm{mg} / \mathrm{dl}$ as cut-off values and 16.2\% GDM prevalence when taking only $2 \mathrm{hr}$ plasma glucose for analysis. $^{21}$ The prevalence of GDM in Asian-Indian women was found $13.4 \%$ in a study conducted by Balaji, et al. in 2009-10, in which a total of 1463 pregnant women underwent $75 \mathrm{~g}$ oral glucose challenge test (GCT) according to DIPSI criteria. ${ }^{22}$ Similar results found in present study, a total 800 subjects screened by single and simple step DIPSI criteria, of which 118 (14.75\%) were diagnosed as GDM at their $1^{\text {st }}$ visit.

Thus, it was analyzed that prevalence of GDM in Jabalpur district was $14.75 \%$ at $1^{\text {st }}$ visit itself. Alpana Singh, B. Uma conducted a study Bhaskar Medical College and Hospital, Hyderabad, and they found $5.7 \%$ incidence of GDM by using the DIPSI method. ${ }^{23}$
Various studies conducted in different parts of India and observed that prevalence varied with different geographical locations and diagnostic methods used. Prevalence was found $6.6 \%$ in Jodhpur Rajasthan, 9.7\% in Uttar Pradesh, 5.2\% in Odisha, $17 \%$ in Kollam district Kerala, $14.42 \%$ in Kanpur Uttar Pradesh, 6.94\% in Jammu Region. ${ }^{24-29}$

We observed positive association of GDM by age group. The prevalence proportion increased with age from $9.8 \%$ in the age group $\leq 20$ years to $32.9 \%$ for the age groups $>30$ years. A study conducted by Seshiah V et al. Gestational Diabetes Mellitus in India concluded that among 891 pregnant women, the mean age was $23 \pm 4$ years. The prevalence proportion increased with age from $15.7 \%$ (confidence limits: $8.6 \%-25.3 \%$ ) in the age group $15-19$ years to $32.1 \%$ (confidence limits: $20.3 \%-46.0 \%$ ) for the age groups $>30$ years. ${ }^{21}$

A study conducted by Wahi $\mathrm{P}$, et al in Jammu showed that a significant proportion of subjects with GDM were overweight $19(30.65 \%)$ and obese 16 (25.8\%). ${ }^{29}$ Similarly in present study, 53 (44.9\%) GDM patients had BMI $>25$ with $27.96 \%$ being obese $($ BMI $>30)$. This was further supported by a study by Kalra, et al. which concluded that significant proportion of subjects with GDM were overweight $22(66.67 \%)$ and obese 6 $(18.18 \%){ }^{25}$ The mean BMI found in GDM positive subjects was $25.32 \pm 4.91$ and $p$ value was $<0.0001$ which was highly significant. A study conducted by Balaji, et al: Diagnosis of gestational diabetes mellitus in Asian-Indian women concluded that the mean BMI of the 1463 pregnant women was $21.5 \pm 4.06 \mathrm{~kg} / \mathrm{m}^{2} .^{22}$ A study conducted by Alpana Singh, B. Uma showed that $39.1 \%$ GDM subjects were having BMI $\geq 25 \mathrm{~kg} / \mathrm{m}^{2}{ }^{23}$

Kalra et al showed that $36.4 \%$ GDM subjects were associated with hypertension. ${ }^{25}$ Similarly, in present study $35(29.66 \%)$ GDM subjects were hypertensive, which was statistically significant. A study conducted by Wahi P et al in Jammu found that $6.45 \%$ GCT positive subjects were associated with hypertension. ${ }^{29}$

A study conducted by Alpana Singh, B. Uma et al. showed that $13 \%$ subjects with history of GDM in previous pregnancy develop GDM. ${ }^{23}$ Similarly, we found that 6 subjects had past history of gestational diabetes, of which $2(33.34 \%)$ subjects diagnosed as GDM even at their $1^{\text {st }}$ visit in present pregnancy, although this was not found significant. Since the study included a single screening, it could not be ascertained whether the remaining 4 become diabetic in later pregnancy. According to Kalra et al. family history of diabetes mellitus was found in $33.3 \%$ of GDM women. ${ }^{25}$ Similarly, in present study $22.88 \%$ GDM women had history of diabetes in their first degree relatives and $16.94 \%$ GDM women had history of diabetes in their second degree relatives. A study conducted by Balaji, et al. Diagnosis of Gestational diabetes mellitus in AsianIndian women concluded that pregnant women who had 
family history of diabetes were $18.3 \% .^{22}$ A study conducted by Wahi $\mathrm{P}$ et al. in Jammu concluded that family history of diabetes mellitus found in $24.19 \%$ of subjects. ${ }^{29}$ Jain R, et al. Gestational diabetes as perinatal and maternal complication concluded that GDM subjects had $20.6 \%$ positive family history of diabetes. ${ }^{28}$

Since the diagnosis of GDM at the $1^{\text {st }}$ antenatal visit will not identify all subjects, it may be concluded that more pregnant women will become diabetic at repeat testing.

\section{CONCLUSION}

The DIPSI test is simple, cost effective and economic test. The test can be easily performed in high volume hospitals in a small time and economically and the patients were more at ease as they were not fasting. There is a need to enhance awareness amongst health care providers especially working at rural setups about the maternal and perinatal risk of GDM and the ease of the screening test and its interpretation.

The prevalence of GDM in present study was $14.75 \%$ at 1 st antenatal visit itself. So, to find out the exact prevalence of GDM, repeat screening should be done at recommended interval at least in high risk population.

\section{Recommendations}

The recommendations for the universal screening for GDM in all antenatal clinics should be laid down because of high prevalence rate and the significant impact it has on maternal and fetal outcome. This will help us in calculating the economic impact as well as designing preventive strategies.

Funding: No funding sources

Conflict of interest: None declared

Ethical approval: The study was approved by the Institutional Ethics Committee

\section{REFERENCES}

1. Metzger BE, Coustan DR. Organizing Committee. Summary and recommendations of the fourth international workshop-conference on gestational diabetes mellitus. Diabetes care. 1998 Aug 1;21:B161.

2. Anjalakshi C, Balaji V, Balaji MS, Ashalata S, Suganthi S, Arthi T et al. A single test procedure to diagnose gestational diabetes mellitus. Acta Diabetologica. 2009 Mar 1;46(1):51-4.

3. Magon N, Chauhan M. Diagnosing GDM: role of simple, cost effective, and sensitive DIPSI test. J Obstet Gynecol India. 2014;64(4):299-300.

4. International Diabetes Federation. IDF Diabetes Atlas, 7th edn. Brussels, Belgium: International Diabetes Federation;2015:48,68.
5. International Diabetes Federation. IDF Diabetes Atlas, 7th edn. Brussels, Belgium: International Diabetes Federation;2015:63.

6. Seshiah V, Balaji V, Balaji MS, et al. Prevalence of gestational diabetes mellitus in South India (Tamil Nadu): a community based study. J Assoc Physicians India. 2008;56:329-333.

7. Raja MW, Baba TA, Hanga AJ, Bilquees S, Rasheed, Haq IU et al. A study to estimate the prevalence of gestational diabetes mellites in an urban block of Kashmir valley (North India). Int J Med Sci Public Health. 2014;3:191- 5.

8. Swami SR, Mehetre R, Shivane V, Bandgar TR, Menon PS, Shah NS. Prevalence of carbohydrate intolerance of varying degrees in pregnant females in western India (Maharashtra): a hospital- based study. J Indian Med Assoc. 2008;106:712- 4, 735.

9. Bhatt AA, Dhore PB, Purandare VB, Sayyad MG, Mandal MK, Unnikrishnan AG. Gestational diabetes mellitus in rural population of Western India- Results of a community survey. Indian $\mathbf{J}$ Endocrinol Metab. 2015;19:507- 10.

10. Seshiah V, Balaji V, Balaji MS, Sanjeevi CB, Green A. Gestational diabetes mellitus in India. J Assoc Physicians India. 2004;52:707- 11.

11. Arora GP, Thaman RG, Prasad RB, Almgren P, Brøns C, Groop LC et al. Prevalence and risk factors of gestational diabetes in Punjab, North India: Results from a population screening program. Eur $\mathbf{J}$ Endocrinol. 2015;173:257- 67.

12. Gopalakrishnan V, Singh R, Pradeep Y, Kapoor D, Rani AK, Pradhan S, et al. Evaluation of the prevalence of gestational diabetes mellitus in North Indians using the International Association of Diabetes and Pregnancy Study groups (IADPSG) criteria. J Postgrad Med. 2015;61:155- 8.

13. Kayal A, Anjana RM, Mohan V. Gestational diabetes- An update from India, 2013. Diabetes Voice 58, 2013. Available at http://www. idf.org/gestational- diabetes.

14. Agarwal S, Gupta AN. Gestational diabetes. J Assoc Physicians India. 1982;30(4):203-5.

15. Narendra J, Munichoodappa C, Gurudas A, Ramprasad AV, Madhav T, Vijayalakshm N. Prevalence of glucose intolerance during pregnancy. Int J Diab Dev Countries. 1991 Apr;11(2):2-4.

16. Seshiah V, Balaji V, Balaji MS, Sanjeevi CB, Green A. Gestational diabetes mellitus in India. Japi. 2004 Sep 21;52:707-11.

17. Seshiah V, Balaji V, Balaji MS. Scope for prevention of diabetes: focus intrauterine milieu interieur' J Assoc Physicians India. 2008;56:109-113.

18. Seshiah V, Balaji V, Balaji MS, Panneerselvam A, Kapur A, Panneerselvam A et al. Pregnancy and diabetes scenario around the world. India. Int $\mathbf{J}$ Gynaecol Obstet. 2009;104(Suppl 1):S35-S38.

19. Seshiah V, Balaji V, Madhuri B. Gestational Diabetes Mellitus. A Perspective. Gestational Diabetes. Croatia: InTech;2011:21-40. 
20. World Health Organization. Diabetes mellitus. Tech Rep Ser. 1985;727:20-4.

21. Seshiah V, Balaji V, Balaji MS, Sanjeevi CB, Green A. Gestational diabetes mellitus in India. JAPI. 2004 Sep 21;52:707-11.

22. Balaji V, Balaji M, Anjalakshi C, Cynthia A, Arthi T, Seshiah V. Diagnosis of gestational diabetes mellitus in Asian-Indian women. Indian J Endocrinol Metab. 2011 Jul 1;15(3):187-190.

23. Singh A, Uma B. Incidence of gestational diabetes mellitus and its outcomes in a rural population. $\mathrm{J}$ Evol Med Dental Sci. 2013 Apr 1;2(13):1982-7.

24. Kalra P, Kachhwaha CP, Singh HV. Prevalence of gestational diabetes mellitus and its outcome in western Rajasthan. Indian J Endocrinol Metab. 2013 Jul;17(4):677.

25. Swaroop N, Rawat R, Lal P, Pal N, Kumari K, Sharma P. Gestational diabetes mellitus: study of prevalence using criteria of diabetes in pregnancy study group in India and its impact on maternal and fetal outcome in a rural tertiary institute. Int J Reprod Contracept Obstet Gynecol. 2015;4(6):1950-3.
26. Nanda SS, Dash K, Dash S, Misra S, Das S. Screening of gestational diabetes mellitus with $75 \mathrm{gm}$ OGTT and its effects on feto-maternal outcome. Screening. 2014;2:340-4.

27. Shreekanthan K, Belicita A, Rajendran K, Vijayakumar A. Prevalence of Gestational diabetes mellitus in a medical college in South India: A pilot study. Indian J Clin Pract. 2014;25(4):342-7.

28. Jain R, Pathak RR, Kotecha AA. Gestational diabetes: Perinatal and maternal complication in 2428 weeks. Int $\mathrm{J}$ Med Sci Public Health. 2014;3(10):1283-8.

29. Wahi P, Dogra V, Jandial K, Bhagat R, Gupta R, Gupta $S$ et al. Prevalence of gestational diabetes mellitus (GDM) and its outcomes in Jammu region. $\mathbf{J}$ Assoc Physicians India. 2011 Apr;59(4):227-30.

Cite this article as: Guin G, Dadhich R. Gestational diabetes: know your risk by simple and single step criteria (DIPSI). Int J Reprod Contracept Obstet Gynecol 2017;6:5107-12. 